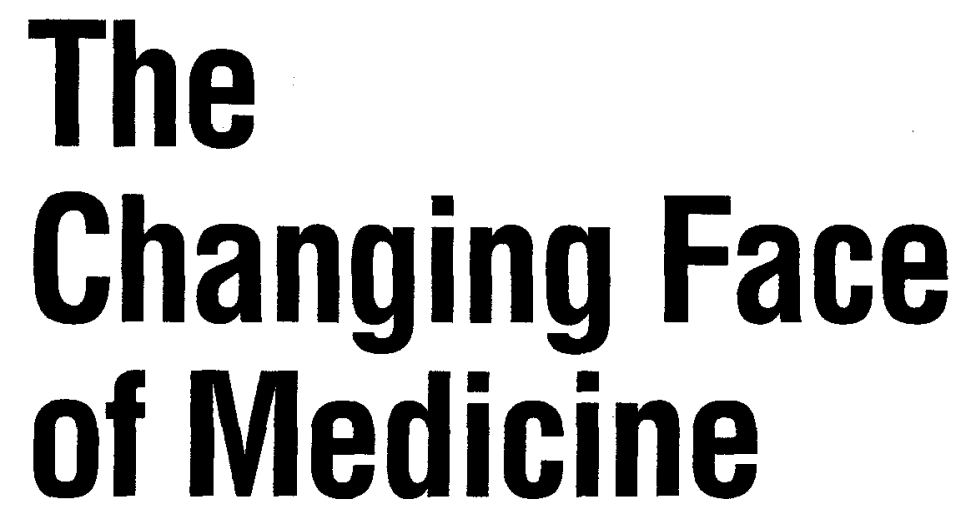

\title{
WOMEN DOCTORS AND THE EVOLUTION OF HEALTH CARE IN AMERICA
}

\section{Ann K. Boulis Jerry A. Jacobs}

\section{ILR Press}

an imprint of

Cornell University Press ITHACA AND LONDON 


\section{Copyright $\odot 2008$ by Cornell University}

All rights reserved. Except for brief quotations in a review, this book, or parts thereof, must not be reproduced in any form without permission in writing from the publisher. For information, address Cornell University Press, Sage House, 512 East State Street, Ithaca, New York 14850.

First published 2008 by Cornell University Press

Printed in the United States of America

Library of Congress Cataloging-in-Publication Data

Boulis, Ann K., 1968-

The changing face of medicine : women doctors and the evolution of health care in America / Ann K. Boulis, Jerry A. Jacobs.

p. cm. - (The culture and politics of health care work)

Includes bibliographical references and index.

ISBN 978-0-8014-4446-3 (cloth : alk. paper)

1. Women physicians-United States. 2. Medical care-United

States. I. Jacobs, Jerry A., 1955-. II. Title. III. Series.

R692.B675 2008

$610.82-\mathrm{dc} 22$

Cornell University Press strives to use environmentally responsible suppliers and materials to the fullest extent possible in the publishing of its books. Such materials include vegetable-based, low-VOC inks and acid-free papers that are recycled, totally chlorine-free, or partly composed of nonwood fibers. For further information, visit our website at www.comellpress.comell.edu. 
This book is dedicated

to our daughters,

Sophia and Renie Harris

and

Elizabeth and

Madeleine Jacobs

\author{
Property at

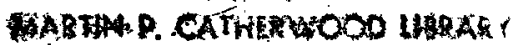

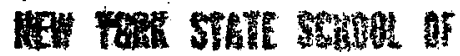

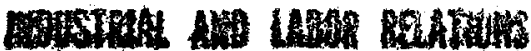

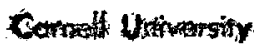




\section{Contents}

Acknowledgments

1 Introduction 1

2 Feminization of an Evolving Profession 15

3 Applying for Change 41

4 The Gendered Map of Contemporary Medicine 65

5 Gender, Sorting, and Tracking 86

6 Work, Family, Marriage, and Generational Change 113

7 Women Physicians Caring for Patients 132

8 Medicine as a Family-Friendly Profession? 153

9 Conclusion: A Prognosis for Gender and Medical Care 187

Appendix 213

Notes $\quad 229$

Bibliography 235

Index $\quad 261$ 


\section{Acknowledgments}

This project has had a long gestation, and consequently we have accu-
mulated many debts along the way. The research presented here has been
funded by research grants from the Josiah H. Macy Foundation and the
Robert Wood Johnson Foundation, and a National Academy of Education
Post-Doctoral Fellowship for Ann Boulis funded by the Lyle M. Spencer
Foundation.
We are grateful to Dr. June Osborn, president of the Macy Foundation,
and Dr. Cathy DeAngelis, editor of the Journal of the American Medical As-
sociation, who played a central role in organizing the Macy Foundation
Conference in 2006 where the issues addressed in this book were discussed
(Hager 2007 ). At Cornell University Press, Fran Benson has been very en-
couraging since the first outline of this project was put together some years
ago. Sioban Nelson read several drafts of the manuscript and offered very
thoughtful and detailed advice.
We wish to acknowledge the valuable research assistance provided by
Arielle Kuperberg, Terry Labov, Daniella Main, and Kristin Turney. Ruth
Schwartz Cowan, Jason Schnittker, and Chloe Bird organized seminars and
professional panels that gave us the opportunity to present some of our
findings. Charles Bosk met with us shortly after the inception of this project
and has provided collegial advice as we brought this study to fruition.
We acknowledge the Association of American Medical Colleges (AAMC)
for sharing its data on entering and graduating students. The conclusions
presented here are our own and do not reflect those of the AAMC. Similarly,
we thank Linda Sax and William S. Korn at the UCLA Higher Education 
Research Institute for generously providing tabulations of their unique data on American college freshmen.

We have benefited from lengthy discussions with Dr. Stephanie Abbuhl and $\mathrm{Dr}$. Judith Long regarding many issues examined here, especially about the role of women in academic medicine. Special thanks to Gus Harris and to Renee and Matt Boulis for their support throughout this project. 
The Changing Face of Medicine 


\section{Introduction}

Betty Friedan was very proud of her daughter the doctor. Friedan's 1963 book The Feminine Mystique helped to spark the second wave of the women's movement during the 1960s, and Friedan went on to help establish the National Organization for Women. Her daughter, Emily, entered Harvard Medical School in 1978, just as the number of young women in medical school classes began its rapid ascent.

Encouraging one's daughter to pursue a career in medicine is no longer an unusual idea restricted to feminist leaders who happen to be Jewish. In fact, Americans are now more likely to report that they feel comfortable recommending a career in medicine for a young woman than for a young man. The Gallup Organization has polled Americans on this subject periodically since the Second World War (see Figure 1.1). In 1950 more than one quarter of those sampled reported that they would recommend a career in medicine for a young man, but only 2 percent would do so for a young woman (Saad 2005). ${ }^{1}$ The question was not asked again about young women until 1985. By this time the number of respondents who volunteered medicine as a career for young men had declined to fewer than 10 percent, but the level of support for young women physicians had grown to nearly the same level. Since 1998 the proportion who would recommend a career in medicine to a young woman has exceeded that for young men.

A career in medicine is now the top recommendation for young women, surpassing the most prominent alternatives-nursing, teaching, computers, and business-by a wide margin. Moreover, the overall level of endorsement for careers in medicine has rebounded from its lows during the 1980s. We think Betty, who passed away in 2006, would be pleased to know of this trend. 


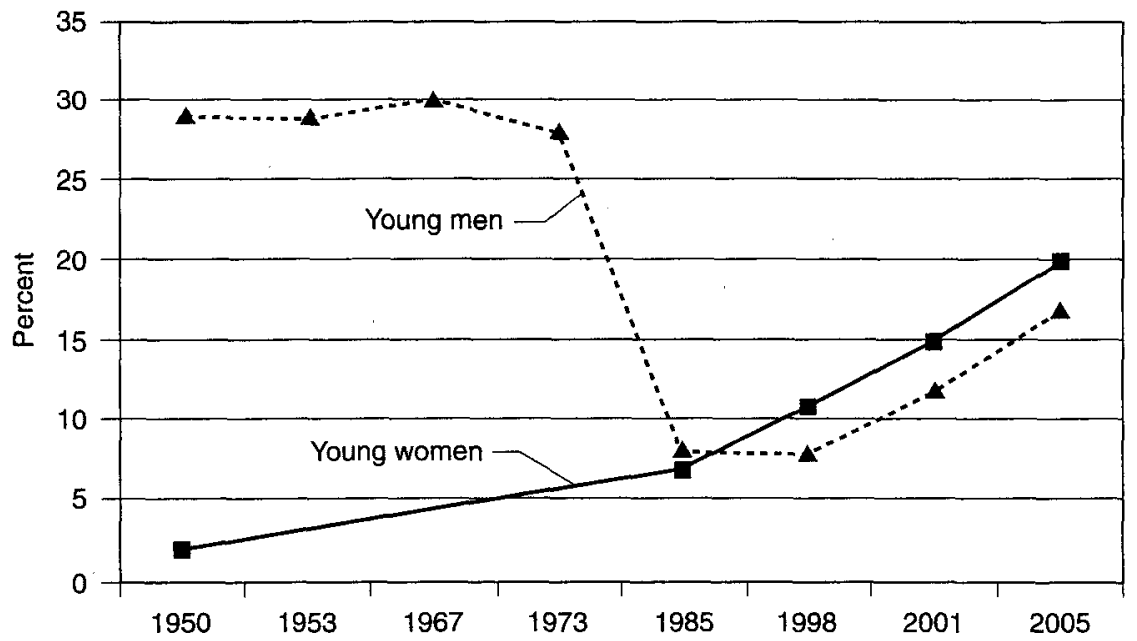

Figure 1.1. Trends in Advice to Young Men and Women. Source: Gallup Organization, Saad 2005.

For Friedan, the women's movement was principally about opening up avenues of opportunity for daughters which had previously been reserved for sons. Whereas feminist politics in recent years have centered on debates about abortion, contraception, and gay marriage and parenting, it may be useful to remember that expanding new career possibilities for young women was central to the original agenda. From this vantage point, the burgeoning numbers of women entering the medical profession surely constitutes a success story. Female physicians are not simply a symbol of women's accomplishments; they also constitute a significant fraction of the highestearning women in the United States. In 2000 they represented nearly one in ten women who earned more than $\$ 100,000{ }^{2}$

Since the 1970s, women have made significant progress in the U.S. medical profession. Most notably, between 1970 and 2005 women's share of seats in medical schools increased from 11 percent to 48.9 percent (AAMC 2006). During the same period, women's numerical representation among practicing physicians increased nearly ninefold, from 25,000 in 1970 to 225,000 in 2002. In this book we examine whether women's entry into medicine represents a success for feminism or if the story is more complex than the term "success" might suggest. We first document why and how women's representation among physicians in the United States has grown so dramatically since 1970 . We then assess the place that women currently occupy in the medical profession and examine how they came to occupy this place. And finally, we consider the impact of this demographic transformation on the provision of health care services. Specifically, we address four 
questions: (1) How can the feminization of medicine in the United States best be explained? (2) How and why do the career locations and experiences of male and female physicians differ? (3) How are the family lives of physicians changing as the need to balance work and family becomes more salient? and (4) What effect has the feminization of U.S. medicine had on the daily practice of medicine and on the medical profession?

Has the entry of women into the profession resulted from a decline in the status of medicine? In other words, does women's entry represent a turning point in the status of the medical profession? Has the entry of women led to a further deterioration in the status of the profession, impacting the women themselves as well as their male counterparts? Have women become full and equal members of the profession, or have they become ghettoized in a small set of low-paying, low-status specialties? Once they don their white coats, have women begun to change the way medicine is being practiced? Finally, are women bringing a heritage of nurturance and caring to the science of medicine, or do male and female physicians trained in the same procedures make the same diagnoses and deliver the same expert care in essentially interchangeable ways? Will women change the nature of the medical profession and its social position?

Our study follows women (and men) as they enter the medical profession. We chart the pathways that men and women traverse as they become doctors. By comparing these processes for different generations of physicians during a period of rapid change, we are able to better understand how women entered this most prominent of professions and, once there, where they land.

Are gender differences in medicine the result of the choices made by individual women, or do gendered institutions also play an important role? The bulk of research to date highlights the role of individual choice and underplays the effects of institutional arrangements and social pressures. By tracing changes over time, we are better positioned to assess the evolution of choices and constraints that women have faced.

When patients come into a family practice setting, or find themselves in an emergency room or specialist's office, does it matter if the physician is a woman or a man? Will the nature of the encounter be different? Will female physicians be consistently more collegial, more caring, and more attuned to psychosocial issues? Will diagnoses, referrals, procedures, and prescriptions be the same regardless of the physician's gender? Are there gender differences that pertain across the board, or are differences in practice restricted to a limited set of ambiguous conditions or to distinct parings of physicians and patients?

And what will happen to the structure of the profession when women physicians are as numerous as men? Will the increasing number of women physicians change the focus of medical research or influence the leadership style of organized medicine? Will this dramatic demographic change cause 
all physicians, regardless of gender, to employ a more collaborative approach with other health care providers? Will the presence of women lead to the creation of more family-friendly supports within the profession?

In endeavoring to answer these questions, we draw on a wide array of data sources. Since most sources of data have both strengths and weaknesses, our approach is to cast a wide net in order to gather as much information as possible on the evolution of gender and medicine. Our analysis of the processes of recruitment into the profession takes advantage of multiple longitudinal data sources, including a series of national surveys of college students' career plans which span the 1970s, 1980s, and 1990s and data from the Association of American Medical Colleges (AAMC) surveys of prospective and matriculating medical students before and after graduating from medical school. In order to understand the career experiences of physicians, we analyzed data from 1996 and 2004 on physicians' attitudes and practices from the Community Tracking Study, a nationally representative longitudinal sample of doctors. Our examination of changes in the family lives of physicians draws on data from the 1980, 1990, and 2000 U.S. censuses.

We supplement these rich and varied quantitative sources with dozens of in-depth interviews with female physicians at all stages of the career cycle. We also posted questions on-line at the MomMD and the Student Doctor Network Web sites, and we monitored scores of postings that followed. Both sites include frequent discussions of gender issues in medicine. These data sources are described in more detail in the Appendix.

\section{Perspectives on Gender and Medicine}

We draw on three main perspectives on gender and work to inform our answers to the four questions delineated earlier. The first perspective, which we refer to as personal choice, suggests that gender differences in the workforce stem primarily from differences in the choices that men and women make as they pursue education and paid employment. In other words, gender differences in the status of male and female physicians reflect preferences and values that women bring with them into the medical profession (Hinze et al. 1997; Grant et al. 1990). More specifically, this viewpoint asserts that women physicians choose to work fewer hours than men and gravitate toward primary care roles because they give higher priority to the care of their families.

The personal choice perspective also emphasizes the relationship between personal values and gender differences in career choice. The crux of this perspective is best articulated by Carol Gilligan in her book In a Different Voice (1982). Gilligan holds that women are generally less competitive and status conscious and more sensitive, caring, and concerned about others' feelings than are men. In the context of medicine, the "different voice" 
thesis predicts that women will be more interested in close relationships with their patients and less interested in high earnings than their male counterparts. Advocates of the different voice perspective suggest that the tendency for female physicians to spend more time with patients (Dorschner 2003; Ross 2003; Fang et al. 2004) stems primarily from women's desire to know and care for their patients rather than simply treating their specific medical conditions. They also believe that it is the caring nature of women medical students which leads to their disproportionate interest in serving underprivileged patients (Crandall et al. 1993).

The second perspective, which we refer to as the institutional discrimination thesis, suggests that specific industry and organizational characteristics and the behaviors of other key groups in the health services workforce are responsible for many of the disparities between male and female physicians. One of the most common theories in the discrimination perspective is the "structural difference" view (Kanter 1977). This theory holds that differences between men and women workers reflect gender differences in status and power in the organization or the profession. In the medical context it suggests that observed gender differences in practice or status stem from women's weaker organizational or professional position. Advocates of the structural discrimination perspective see the tendency for women to spend more time with patients very differently from those who believe that women are inherently more caring. These analysts maintain that the propensity for women physicians to spend relatively more time with patients results from the greater needs of women physicians' patients and the tendency for women physicians to work as employees. In fact, research shows that a large portion of the time differential among primary care physicians stems from the fact that women physicians see more women patients who often need time-consuming pelvic exams (Franks and Bertakis 2003). In a similar light, researchers have shown that women physicians are more likely to be employees than are their male counterparts, and physicians in such settings spend more time in each patient visit (Kikano et al. 1998). Finally, the structural discrimination perspective offers an explanation of why women physicians are actually less likely to provide charity care even though studies suggest that as graduating medical students, women are more amenable than men to providing such care (Cunningham et al. 1999; Crandall et al. 1993). The evidence suggests that physicians who work as employees spend less time offering their services for free; consequently, women's concentration in positions as employees, typically in hospital settings, accounts for their lower rate of charity care.

A closely related phenomenon involves the social expectations or behaviors of physicians' colleagues and patients. At one extreme, women might encounter more harassment and less mentoring support. At the other, gender-linked behaviors might also be more subtle but the effects no less 
important. For example, assumptions regarding patients' preferences might cause men to assign breast surgeries to their female colleagues in a general surgery practice (Cassell 1998; McMurray et al. 2000). In a similar light, the expectation that women are good communicators might cause patients with emotional problems to seek them out, and this process of sorting may explain why female physicians see more patients with complex social problems (McMurray et al. 2000).

The third perspective that motivates our analysis focuses on social change. One of the more prominent theories maintains that increases in the representation of women in an occupation are related to declines in the status of the field. The underlying idea here is that women constitute a surplus labor force, and that they enter professions only when more desirable workersnamely, men-are no longer interested.

The dramatic influx of women into medicine and other occupations has prompted social scientists to investigate demographic changes in the labor force (Reskin and Roos 1990; Strober 1984; Cohn 1985). This research examines changes in the status of women workers that accompany their entry into an occupation such as medicine. In particular, Reskin and Roos (1990) suggest that women's entry into male-dominated occupations tends to occur in a similar fashion regardless of the specific profession. A shortage of male employees prompts employers to recruit women. The shortage of men is typically due to a decline in the status of the occupation. In some cases the impetus for the initial departure of men from an occupation is a technological shift that lowers skill levels and earnings in the field. Reskin and Roos also find that, in general, women's entry into male-dominated fields does not result in true integration. Rather, women cluster in the least desirable niches of male-dominated occupations-niches with lower pay, fewer required skills, less autonomy, and limited promotion opportunities.

Another aspect of social change involves generational shifts among women physicians. From this perspective, the first groups of women to enter medicine in the late 1960s and 1970s represented "pioneers" who blazed uncharted paths in a male-dominated terrain. Consequently, these "trailblazers" faced different expectations and challenges than did the "settlers" - those women who followed in their footsteps. The first small, elite group had few role models, and were committed to proving that women could succeed. They also felt so privileged to enter the profession that they tolerated unequal treatment. Empowered by their growing numbers and increasing attention to women's professional issues in the broader labor force, many among the generation of women physicians who entered medicine during the 1990s and beyond seek a fulfilling family life along with the satisfactions of engaging professional work. At the same time, it may be that work expectations are shifting for male physicians as well, as they are increasingly likely to find themselves in dual-career families. 
We challenge the assumptions of many of these perspectives along the path to developing a new understanding of women's representation in medicine. Our thesis is that the medical profession reflects and exemplifies broader changes in women's roles in American culture and society. Women's status has changed as a result of political developments (specifically the women's movement); social and cultural changes in education, work, and family life; and the economic forces buffeting American society.

Women's entry into medicine reflects broader accomplishments in the labor force and the professions as well as the unique institutional changes occurring in the U.S. health care system. Our research situates the medical profession in the context of the evolution of women's position in American society. Women's achievements in medicine, however, continue to fall short of complete equality in a number of important areas, as is the case with women in the broader labor market. Careers in medicine are especially demanding in terms of training, working time, and professional commitment, and thus the dilemmas of balancing and integrating work and family life are especially salient among physicians. The economic, technical, and organizational landscape of medicine has rapidly evolved since the 1970s with the rise of managed care and other pressures to rein in the costs of medical care. These forces have limited the extent to which women could remake the medical profession in their own image. Nevertheless, we expect that the influence of women physicians on the medical landscape will continue to grow as they make inroads throughout the profession and in positions of professional leadership.

Relative to other occupational and professional choices for women, medicine ranks high in terms of financial rewards and personal satisfaction. Thus women's successes in the field of medicine are not principally due to a sharp decline in the desirability of careers in the medical profession, as medicine remains at the top of the occupational status hierarchy. At the same time, medicine is a highly stratified and internally differentiated profession, and the inequality within the profession compounds the difficulties women face in pursuing complete equality. Indeed, there are indications of increasing inequality among physicians. Marked disparities by gender remain in specialty areas, ownership and employee status, faculty representation, and leadership positions. Discrimination persists in some stages of the medical career, in some specialties, and in terms of women's access to positions of leadership. But women also face the challenges posed by institutional arrangements which are at least as salient as the lingering resistance and sexist attitudes of some male physicians. Women over the last generation or so have entered a profession designed for the male breadwinner with a stay-at-home spouse. Intense time demands and continuing professional commitments, with few opportunities to leave and reenter, 
dominate the lives of physicians during their twenties and well into their thirties, spanning most of the childbearing years. Very few women physicians have stay-at-home husbands who provide the kind of support that stay-at-home wives provided an earlier generation of men.

The evidence we have compiled is largely inconsistent with the notion of a "post-pioneer" pattern of female physicians' career choices. We find that women doctors are not dropping out of the labor force, nor are they more likely to marry and have children today than did previous generations. Moreover, the gender gap in work habits and earnings is quickly closing for childless male and female physicians. We also show that women physicians are more similar to other women today in terms of marriage and motherhood than was the case a generation ago. Women physicians face enduring challenges in combining work which are similar in kind, though perhaps more extensive in nature, than those faced by other employed women.

The values that women bring with them to medicine differ from those of their male counterparts. Careers in medicine offer not only financial rewards but also the personal satisfaction of helping others in their times of greatest need. Thus medicine has become a more socially attractive professional option for scientifically oriented women than other technical fields such as engineering. Although evidence indicates that women medical students are more altruistic in their professional goals than are their male classmates, this particular gender gap is not as sizable as one might assume but amounts to only a few percentage points, and changes in the intentions of male and female physicians over time dwarf differences between the two genders. Moreover, the values and preferences of entering medical students are not sufficient to explain subsequent behavior. Ultimately, the structure of the environment in which physicians work and the expectations of peers and patients influence physician behaviors as much as or more than the abstract ideals that physicians hold during and immediately after their training.

Women physicians do interact with their patients in subtly different ways than their male peers, but gender differences in diagnosis and treatment are not extensive. Differences in practice patterns are most evident in areas involving patients' personal privacy and sexually sensitive conditions. As far as the structure of the profession is concerned, women are just beginning to have an impact on the profession and the way medicine in practiced, and more change is likely as their representation continues to grow.

This book is a case study of one profession that plays a key role in the health care sector, which now represents about one seventh of the U.S. economy. It examines the most dramatic demographic change in this sector in the last century. But the issues we raise are likely to be of interest more broadly for what they say about the changing roles of women in contemporary society. Women's entry into medicine is taken as dramatic evidence that the barriers to opportunity for women are rapidly falling in 
America. Does the experience of female physicians to date bear out this optimistic view? An alternative view is that gender roles remain deeply entrenched in our institutions and culture. Specifically, the gender division of household labor continues to constrain the choices of all women (Moen 2003). The trade-offs between work and family may be clearest in the most demanding professions, such as law and medicine, which require a high degree of professional devotion (Blair-Loy 2003).

Our study builds on the fine histories of women in medicine written by Walsh (1977), Morantz-Sanchez (1985), and More (1999). The analysis presented here focuses on the period since 1970, thus complementing the important studies of Bowman and colleagues (2002) and Bickel (2000). Lorber (1984) examined the experiences of the generation of women who pioneered the transformation of the profession. With the benefit of additional decades of perspective, we are in a position to examine whether the role of gender in medicine is changing.

\section{Women's Entry into Medicine}

Since the 1970 s the face of students at American medical schools has changed markedly, with women rapidly approaching 50 percent of entering medical students. While women's arrival has been widely noted, few studies have directly confronted the question of how and why this change is occurring. The next two chapters of the book are devoted to trying to explain this trend. Is women's entry a reflection of the plummeting status of the medical profession, or are the reasons more varied and complex? We examine several interrelated aspects of professional status, including earnings, autonomy, and prestige, as well as the political clout of the American Medical Association. We consider specific historical developments, such as changes in government reimbursement policies and the ebb and flow of concerns over malpractice insurance premiums. We pay considerable attention to the interest levels in the profession exhibited by young men. As we review the 1970s, the 1980s, and the 1990s in detail, we do not assume that the same factors play the same roles in each decade. The series of challenges to the status of the profession is the central concern of chapter 2 .

In chapter 3 we set the feminization of medicine in the broader context of changing gender roles in society at large. We examine factors that influence the degree of preparation for careers in medicine, including the extent of women's education, the rates at which young women take math and science courses in high school, and the number of women graduating from college with degrees in biology.

We find that women have entered medicine not so much because of the flight of men but rather because many barriers to access have eroded. The timing of women's entry, as well as the ups and downs of men's applications 
to medical school, does not map onto the timing of challenges to the authority, status, and earnings of the profession. In many ways, women's entry into medicine is in line with the broader patterns of women's growing share of the labor market, leadership, and power as a whole. Women earn an increasing proportion of college degrees, and they have pursued historically male-dominated academic tracks in increasing numbers, and these changes are beginning to influence our society. Women's entry into the medical profession reflects and exemplifies these trends.

Changes in women's roles are not confined to the United States, nor is the feminization of medicine a uniquely American phenomenon. Our review of the trends in physician employment patterns in developed countries shows an increased representation of women in all of the thirty-five countries examined. Indeed in many of these countries women's share of the profession exceeds that in the United States. In conjunction with this analysis, we discuss the role that foreign-born physicians have played in the feminization of medicine in the United States. Much of our story, however, is uniquely American. The organization and financing of health care differs sharply from that in many other countries, and the evolution of medicine in the United States has followed a distinctive trajectory (Riska 2001). In short, the evolution of gender and medicine sketched in this book is inextricably linked to the distinctively American features of our medical system. Further research will be required to detail fully which elements of our story resonate in other countries.

\section{Careers in Medicine}

Next we turn to women's careers in the profession. There are many aspects of the opportunity structure to examine. Traditional indices include earnings, specialties, and access to leadership positions. We are also interested in a number of nontraditional measures of career success, such as the ability to combine work and family. To the extent possible, we address these questions historically, examining how the various gender gaps have evolved as women's representation in the medical profession has increased.

We start in chapter 4 by describing the gendered landscape of the medical profession. We examine the distribution of women by specialty, employee and ownership status, involvement with research, faculty appointments, and leadership positions. We map the connection between these positions in the profession onto earnings disparities among physicians.

Chapter 5 turns to a more detailed consideration of gender and medical specialties. We explore the historical basis of specialty practice in order to understand better how the connection between specialties and gender came to take its current form. We also examine the process of sorting into specialties that occurs during medical school. Do the values and preferences 
women and men bring into the profession explain their choice of specialties? What role do experiences during medical school play in subsequent career choices? We also examine careers in academic medicine. In this area we seek to resolve an apparent paradox: women express more interest in pursuing academic careers but end up being underrepresented in this segment of the profession. We seek to pin down the role that medical school experiences play in this process. The emergence of the clinical educator track provides a new context for women's entry into academic medicine.

Women continue to occupy a disadvantaged place both in medicine and in the broader professional labor market. This disadvantage stems from lingering discrimination in the workplace, and from the persistence of organizational arrangements that fail to accommodate the needs of parents in a labor force dominated by members of dual-career families (Jacobs and Gerson 2004). Those who suggest that gender differences in physicians' status stem from the tendency for women to choose "controllable" lifestyles and less procedure-focused specialties have not adequately acknowledged how social forces such as male chauvinistic faculty, colleagues, and patients circumscribe the opportunities of women and men physicians. The "choice" explanation simply ignores how social factors have contributed to the structure of medical education and medical work.

In chapter 6 we examine motherhood and marriage. Here we further explore the contrast between the pioneers and the settlers. Are women physicians able to combine work and family? Do they marry at the same rates as women in the general population and to the same degree as their male counterparts? Are women physicians "opting out" of careers in order to spend time with their children? We report surprising evidence regarding the growing length of workweeks for both men and women in medicine, and find little evidence of an increase in part-time employment. We then examine the nature of physicians' families. We find that the status of women has been improving in the families of both male and female physicians. Finally, we examine changing patterns of marriages in which both partners are physicians. The evidence suggests that, despite broadly similar investments in education and training, marriages between two physicians remain far from equal.

\section{Gender Differences in Practice Patterns}

Having explored how women entered medicine and their experiences as physicians, we turn to the question of the consequences for medical care. Does it matter in terms of treatment if physicians are men or women? Now that women constitute a major and growing portion of the American medical workforce, it is essential that we ascertain whether significant gender differences in practice patterns exist. Identifying the existence and etiology 
of such differences will help to ensure that all patients of the U.S. health care system receive the highest-quality care possible and will also help to provide the most equitable work environment for health care providers regardless of gender. Although much research has been done on gender differences in practice, the research is not complete.

The standard view of the relationship between gender and the provision of medical services is that the sex of a physician does not affect the provision of care to patients. Because physicians are carefully screened and rigorously trained, patients can count on physicians to diagnose, treat, and refer patients as medically indicated regardless of whether they wear pants or skirts under their medical garb. Although they note that there are some sex differences, some researchers, such as Mattila-Lindy and colleagues (1998), conclude that socialization into the medical profession makes physicians' practices more alike and diminishes gender differences. While there is no reason to suspect that either male or female physicians provide systematically inadequate care, a variety of perspectives suggest that gender differences in practice styles may exist. One possibility, in keeping with the "different voice" perspective, is that women provide more nurturing care because they are more interested in the satisfaction of their patients.

Another possibility, motivated by the discrimination perspective, is that gender differences in practice stem from the lower status accorded to women in terms of their social roles and organizational positions. For example, the reluctance of nurses to support female physicians might force female doctors to perform a higher portion of routine procedures themselves (Gjerberg and Kjølsrød 2001; Wear and Knight-McNulty 2004; Zelek and Philips 2003). ${ }^{3}$

Similarly, it could be that the gender stereotypes of patients contribute to gender differences in practice (Street 2002). The social change perspective would focus on changes across generations of women physicians and the extent to which the growing representation of women is changing the practice of medicine.

In addition to these perspectives, we examine a fourth possibility: that gender differences are most likely to emerge in the treatment of specific sex-linked diseases, especially, though not exclusively, those involving personal privacy (Bouchard and Renaud 1997; Britt et al. 1996; Ivins and Kent 1993; Fang et al. 2004; Lurie et al. 1997). For example, a female patient might be more reluctant to raise an issue of vaginal itching with a male physician, while a male patient might feel less comfortable raising potential concerns about a prostate condition with a female doctor. At the same time, physicians might be uncomfortable in exploring certain conditions or performing certain procedures with patients of the opposite sex (Lurie et al. 1998).

In chapter 7 we assess these issues and find evidence that women physicians on average do approach patients differently, employing a more 
collegial approach to the doctor-patient relationship and prioritizing psychosocial issues more than their male colleagues. Research on physician communication, however, highlights similarities between men and women as well. Thus researchers on doctor-patient interactions frequently suggest that physicians of both genders can improve their communication skills.

We present an analysis of vignettes from the Community Tracking Study (CTS) physician survey, which includes physicians' reactions to a series of model patients with presentations designed to suggest multiple appropriate treatment plans. The results reveal a gender effect for sexually sensitive conditions even after differences in practice environment are acknowledged.

With respect to the daily practice of medicine, the similarities between men and women outweigh the differences. Gender matters far more with respect to time spent with patients and communication styles than it does with respect to diagnoses or even treatment regimes. The gender of physician and patient can be of greater significance in areas of personal, especially sexual, privacy.

Chapter 8 examines the question whether medicine is becoming a familyfriendly profession. We find that many physicians are working as many hours as ever. We examine the historical roots of the medical culture of long workweeks and find that despite this culture, many physicians express an interest in working less. Given the prevalence of this interest in reduced hours or part-time work, we explore the availability of part-time opportunities and consider the barriers that inhibit more physicians from taking advantage of these choices. We conclude this discussion by examining how physicians handle the demands of family life in the context of extensive professional commitments.

In the final chapter of the book we take stock of the argument and evidence, and discuss the prospects, for further gender integration of medicine in the coming years. Will women emerge as a new majority of physicians? Will they help to foster a more caring, patient-centered medical care system, or will physicians increasingly leave primary care to physicians' assistants and other medical care practitioners? We also discuss the prospects for women's leadership in medicine and the impact women have had on research on women's health.

In this book we examine how women entered medicine, how they are faring in the rapidly evolving medical system, how they are managing to integrate and balance work and family, how they practice medicine on a day-to-day basis, and how they are changing the system of medical care in the United States. These large themes are interconnected in many ways, and the answers to each of these questions echo throughout the other analyses.

Although individual choices play a significant role in determining women's place in medicine, they cannot explain the origins and implications 
of this profound demographic change. In contrast to much of the available literature, we repeatedly find that the entry of women into medicine, their place in the profession, and their influence on medical practice stem from broad changes occurring throughout American society, from lingering traditional attitudes and arrangements and from independent structural changes in the profession.

The medical profession has been undergoing many fundamental changes in recent decades. In some ways the pace of change regarding gender roles has been slower than other developments, and slower in the United States than has been the case in a number of other countries. As women increasingly become a critical mass in the profession, especially in some specialty areas, they are increasingly poised to make a profound difference in how the medical profession operates. Thus the biggest changes with respect to gender and medicine may lie ahead. 


\section{2}

\section{Feminization of an Evolving Profession}

Ov ver the past several decades health policy researchers and social scientists have debated the status and prestige of the medical profession. While there is nearly universal agreement that medicine enjoyed a uniquely privileged place in our society during the 1950s and 1960s, in the 1970s some policymakers and social researchers began to observe and forecast declines in the earnings, autonomy, control, and prestige of physicians in the United States (McKinlay 1977; Haug 1973). Although the voices predicting that the sky is about to fall on modern medicine have grown in number over time, until recently they have been matched by more optimistic observers who maintain that political and economic pressures have done relatively little to challenge the dominant position of medicine in American society (Mechanic 1991; Freidson 1994). Regardless of the debate over the status of medicine as a profession, however, it is clear that the work experiences of the average physician have changed dramatically since the early 1970s. Most notably, today, physicians at all levels of the profession have significantly less capacity to set prices for their services and to determine their earnings. They are also increasingly likely to face expectations regarding treatment patterns and resource use from both the government and private insurers (Culbertson and Lee 1996; Kelly and Toepp 1994), and they are significantly more likely to face a demanding and critical patient population (Mechanic 2003).

As suggested previously, social researchers (Riska 2001) and physicians (Ross 2003; Levinson and Lurie 2004; Hall 2004) have questioned the implication of women's growing presence in the medical profession. A commonly voiced concern is that increases in the representation of women in the profession will inevitably lead to declines in the status, autonomy, and 
earnings of all physicians. This concern is based on the assumption that there is an inverse relationship between the status of the medical professional and women's representation in it. For example, Riska (2001) points out that women's representation in medicine was relatively high in the Soviet Union, although the status of the profession was quite low compared with that in Western countries. In contrast, over the course of the late nineteenth and most of the twentieth centuries, medicine in the United States had a relatively privileged status, while women practitioners were scarce. Riska places the Scandinavian case in an intermediate position, with more women doctors but lower status for physicians than in the United States.

While much has been said about both the alleged decline in dominance of the medical profession and the increasing representation of women in medicine, few efforts have been made to assess the relationship between these two trends systematically. In this chapter we begin this assessment by comparing reforms in the structure of medicine and gender differences in interest in the medical profession in the United States over time. We suggest that although the interest and presence of women in the medical profession has grown dramatically since the 1970s, there is little reason to believe that women's entry into medicine was prompted by declines in the status and autonomy of the profession. Instead, our account is a multifaceted one that emphasizes different contributing events and processes occurring during each of the last three decades.

The increasing representation of women among medical students during the 1970s resulted from the confluence of three largely independent trends: the removal of barriers to women's entry into medical education, the sharp expansion in the capacity of medical schools, and the end of the military draft for young men. While challenges to the status of the profession had already begun during this decade, the authority and daily practice patterns of physicians remained resilient.

The 1980s are the period that most closely fits the "male flight" explanation, as male applications to medical school fell substantially. But even at this point there are many discrepancies. Physicians' incomes grew briskly during the decade, and the managed care phenomenon had not yet made significant inroads. Also, the "male flight" argument does not predict and cannot explain the limited growth in female applications during this era, especially in light of the dramatic rise in the numbers of female college graduates and biology majors.

The events of the 1990s clearly depart from the "male flight" thesis. During this decade both male and female applications to medical schools rose sharply, even though some of the most serious challenges to professional autonomy and authority were experienced during this time. Women's representation over the 1990s grew despite sharp increases in the number of men interested in pursuing medical careers. 
We begin our discussion with a more detailed review of sociological approaches to the feminization of occupations. The historical analysis is divided into three sections, each of which focuses on a different decade of the thirty-year period in which women's entry into medicine was most pronounced. In each section we ask three distinct questions: (1) Which developments altered the structure of medicine? (2) What were the implications of these changes for the status of the medical profession? and (3) How did these transformations affect women's entry into the profession? We track how the interest of young men and women in medical careers has varied as American medicine has evolved. The analysis in this chapter draws on data pertaining to applications to medical schools, physician incomes, and public esteem for the medical profession in order to pinpoint the times when declines in the status of medicine were most pronounced. We present our own synthesis of trends in the status of the medical profession, drawing on a number of previous studies in this area, including Starr (1982), Stevens (1989), and Freidson (2001), among others.

\section{The Feminization of Occupations}

The dramatic influx of women into medicine and other occupations has prompted social scientists to investigate the processes of occupational segregation and integration (Reskin and Roos 1990; Strober 1984; Cohn 1985). This research examines changes in the status of women that accompany their entry into an occupation such as medicine.

Reskin and Roos (1990) present the most comprehensive analysis of women's entry into male-dominated fields. They examine fourteen cases in which women made significant inroads into occupations previously dominated by men. Eleven of these cases are presented in their book Job Queues, Gender Queues. The commonality that Reskin and Roos posit is that a shortage of male employees prompts employers to recruit women. The shortage of men is typically due to a decline in the status of the occupation. In some cases the impetus for the initial departure of men from an occupation is a technological shift that lowers skill levels and earnings in the field. For example, the advent of computer technology transformed typesetting from a highly skilled manual field to a much cleaner but less skill-intensive keyboarding occupation. Accompanying this shift was a decline in union strength, which contributed to the rapid switch from a predominantly male to a predominantly female occupation. Some currently employed men left, but more important, young men seeking careers avoided this field.

In this account the status of the field declines first. In response, some male incumbents leave, and few new male recruits are to be found. The subsequent recruitment of women simply confirms and crystallizes the debased 
status of the occupation. Feminization of a field is thus seen as the result of a decline in status rather than its initial cause. ${ }^{1}$

This theory holds that employers generally prefer men, and allow women in only when there is a shortage of available men. Faced with such a shortage, employers (or, in the case of the professions, professional gatekeepers) must seek alternative streams of personnel, and thus actively begin to recruit women. The very presence of growing numbers of women itself, however, signals an imminent decline in the status of the profession. This further deters men from entering the field, thus hastening the day when an occupation previously staffed by men becomes a feminine preserve (England et al. 2007). In short, the typical sequence of events is that there is an initial decline in the status of a field, precipitated by some external event, such as a challenge to the authority of the profession, which leads employers or gatekeepers to recruit women, which in turn further contributes to the decline in status of the field.

The implication of this perspective is that women's advances into the professions represent less than meets the eye. While optimists cite the prevalence of women in fields previously dominated by men, Reskin and Roos maintain that such advances rarely represent true equality or full integration. Moreover, they suggest that occupations are unlikely to maintain a balanced gender profile over any significant period of time. Rather the fields are likely to undergo a gender reversal, starting as male fields, then passing through a brief transition period before becoming female fields. Feminization thus involves a tipping point process just like residential segregation, in which the racial composition of neighborhoods can rapidly switch from predominantly white to predominantly black. This approach has been applied to such instances of occupational feminization as teaching in the nineteenth century (Preston 1995) and banking, as in the case of bank tellers during the 1950s (Strober and Arnold 1987) and bank branch managers during the 1970s (Bird 1990), although Wright and Jacobs (1994) suggest that the case of computer programmers during the 1980s is not fully consistent with this approach.

Does this perspective illuminate the influx of women into medicine? As we have seen, the level of interest that men express in a field is a key element of this theory. Consequently, the number of male and female applicants to medical schools is of central interest. ${ }^{2}$

Figure 2.1 presents trends in male and female applications to U.S. medical schools between 1961 and 2004. The number of men who applied to medical schools did in fact decline from 1975 through 1990. Male applications rebounded sharply during the 1990s, however, a period when women's applications also showed their sharpest increases. The pattern of applications thus suggests that a somewhat more complex discussion of women's entry into the profession may be in order. 